\title{
Evaluation of antidiabetic activities of Etlingera elatior flower aqueous extract in vitro and in vivo
}

\author{
Nor Asiah Muhamad Nor ${ }^{1,2}$, Liza Noordin³, Nor Hidayah Abu Bakar ${ }^{4}$, Wan Amir Nizam Wan Ahmad ${ }^{1 *}$ \\ ${ }^{1}$ Biomedicine Programme, School of Health Sciences, Universiti Sains Malaysia, Health Campus, 16150 Kubang Kerian, Kelantan, Malaysia. \\ ${ }^{2}$ Faculty of Health Science, Universiti Sultan Zainal Abidin, Gong Badak Campus, 21300, Kuala Terengganu, Malaysia. \\ ${ }^{3}$ Department of Physiology, School of Medical Sciences, Universiti Sains Malaysia, Health Campus, 16150 Kubang Kerian, Kelantan, Malaysia. \\ ${ }^{4}$ Faculty of Medicine, Universiti Sultan Zainal Abidin, Medical Campus, 20400, Kuala Terengganu, Malaysia.
}

\begin{tabular}{l}
\hline ARTICLE INFO \\
\hline Received on: $16 / 03 / 2020$ \\
Accepted on: $02 / 05 / 2020$ \\
Available online: $05 / 08 / 2020$ \\
\\
\hline Key words: \\
Etlingera elatior, antidiabetic \\
activity, in vitro, in vivo.
\end{tabular}

\section{INTRODUCTION}

Diabetes mellitus (DM) is a chronic condition that occurs when there is an increase in the blood glucose level, which leads to a condition called hyperglycemia (International Diabetes Federation, 2017). Hyperglycemia is one of the crucial factors that plays a role in the development of oxidative stress and actively contributes to the impairment of insulin action and insulin secretion. A large amount of evidence suggests that oxidative stress contributes to the pathogenesis of DM and its complications (Evans et al., 2002; Tiwari et al., 2013). In addition, antioxidant mechanisms are plummeting in diabetic patients, which may

\footnotetext{
*Corresponding Author

Wan Amir Nizam Wan Ahmad, Biomedicine Programme, School of Health Sciences, Universiti Sains Malaysia, Health Campus, 16150 Kubang Kerian, Kelantan, Malaysia.E-mail:wanamir@usm.my
}

further enhance the oxidative stress (Lazo-de-la-Vega-Monroy and Fernndez-Mej, 2013).

Oxidative stress occurs when there is an imbalance in the production of free radicals and antioxidant protection in our body, thus, acting as the primary mediator of cellular damage. The medicinal plant has a variety of chemical families, and the amounts of antioxidants can retard or prevent the oxidation process by stabilizing the free radicals (Patel et al., 2013). In recent years, medicinal plants have started gaining more attention in disease management due to its minimal side effects, and they are relatively low cost with various beneficial health effects. Traditionally, medicinal plants are widely used as a functional food to prevent diseases such as cancer, cardiovascular disease, and diabetes (Yuan et al., 2016).

Etlingera elatior is one of the medicinal plants in Asia that belongs to the ginger family, Zingiberaceae. This plant is widely cultivated in many places throughout Southeast Asia, and it is commonly known as "Kantan" among Malaysians, and 
known as "Kecombrang" and "Kaala" in Indonesia and Thailand, respectively. (Habsah et al., 2005; Lachumy et al., 2010). It is an essential ingredient in Malaysian dishes that is widely used as a spice and freshly consumed as a vegetable (Haleagrahara et al., 2010; Jackie et al., 2011). Interestingly, this plant is potentially used as a source of alternative medicine and has been consumed traditionally to reduce diabetes and hypertension (Chan et al., 2007; Jeevani et al., 2011; Wai Mai et al., 2009). Furthermore, E. elatior has been described to exhibit antimicrobial, antioxidant, anticancer, antidiabetic, antiinflammation, antiageing as well as wound-healing properties (Ghasemzadeh et al., 2015; Habsah et al., 2005; Hueh Zan et al., 2011; Lachumy et al., 2010; Nor Asiah et al., 2019; Srey et al., 2014).

Recently, extensive research has been carried out to study the phytochemical and pharmacological activities of E. elatior through various methods. Furthermore, it consists of high levels of secondary metabolites, such as phenols, flavonoids, glycosides, saponins, tannins, steroids and terpenoids, which contribute to its bioactivity (Chan et al., 2011). Total phenolic and flavonoids contents within E. elatior are found in high amounts in the leaves, flowers, stems, and rhizome (Wai Mai et al., 2009). Moreover, it also exhibits diverse antioxidant activity levels (Chan et al., 2011; Habsah et al., 2005; Ghasemzadeh et al., 2015; Ramasamy et al., 2016). A study by Jackie et al. (2011) reveals that the flower extract of E. elatior has exhibited potent antioxidant activity by increasing the antioxidant enzyme levels, such as superoxide dismutase, glutathione peroxidase, total antioxidants and lowering lipid peroxidation, and protein carbonyl content levels.

Based on the potent antioxidant and anticancer activities of the flower extract, it appears that E. elatior can be found in the northeast of Malaysia (Kelantan) and is a possible source of therapeutic compounds (Ghasemzadeh et al., 2015). Despite numerous pharmacological activities of $E$. elatior that have been previously studied, there is limited research carried out to evaluate the antidiabetic activity of this plant. Thus, this study aims to determine both in vitro and in vivo antidiabetic activities of $E$. elatior flower's aqueous extract through a sonication extraction method.

\section{MATERIALS AND METHODS}

\section{Materials}

Folin-Ciocalteureagent,gallicacid,butylhydroxytoluene, ferric chloride, 1,1-Diphenyl-2-picrylhydrazyl (DPPH) (D 9132), acarbose (PHR 1253), p-nitrophenyl- $\alpha$-D-glucopyranoside (pNPG) (N0877), quercetin high performance liquid chromatography (HPLC) grade (Q4951), potassium chloride, 3,5-dinitrosalicylic acid (DNS) (D0550), starch, $\alpha$-amylase from porcine pancreas (A 3176), and $\alpha$-glucosidase (G5003) (SigmaAldrich Germany). For the animal study, streptozotocin (S0130) was purchased from Sigma Aldrich, Germany; trisodium citrate (1064481000) and citric acid monohydrate (1002441000) from Merck, Germany; metformin from Tokyo Chemical Industry; and sodium pentobarbitone from Alfasan Woerden, Holland.

\section{Sample collection and extraction procedure}

Etlingera elatior flowers were purchased from a local farmer in Kelantan and were authenticated at the International
Islamic University of Malaysia (IIUM), Kuantan, Pahang, with plant voucher PIIUM 0275. Fresh, unopened, uniform-coloured, and no apparent physical defect flowers were selected for this study. Before extraction, the petals were detached from the stalks and then washed to remove foreign particles. Then, it was cut into small pieces and oven-dried at $50^{\circ} \mathrm{C}$ until the weight was constant. The dried sample was ground into powder using a standard laboratory grinder and stored at $4^{\circ} \mathrm{C}$ for the extraction procedure.

Etlingera elatior flower aqueous extract (EEAE) was prepared at the School of Health Sciences (PPSK), Universiti Sains Malaysia (USM), by an ultrasonic-assisted extraction (UAE) method by using a sonicator (SC-221). In this study, water was used as a solvent to emulate the herbal decoction by traditional practitioners. Additionally, when testing on animals, especially when taken orally, water is the best solvent for safety reasons. Initially, $200 \mathrm{~g}$ of the sample powder was sonicated three times with 2,000, 1,800, and $1,400 \mathrm{ml}$ of preboiled distilled water $\left(80^{\circ} \mathrm{C}\right)$, respectively, for 30 minutes (Annegowda et al., 2012). The resultant extract was filtered using grade 1 Whatman filter paper. The combined, filtered extract was frozen overnight at $-20^{\circ} \mathrm{C}$ before freeze-drying. The resulting EEAE powder was then stored in the amber vial at $-20^{\circ} \mathrm{C}$ until further analysis.

\section{Determination of the total phenolic content}

The total phenolic content (TPC) was determined by the Folin-Ciocalteu reagent assay adapted from Singleton and Rossi (1965). The EEAE (1 mg/ml) was diluted in distilled water. $200 \mu \mathrm{l}$ of sample/standard was pipetted into the cuvette, and then $800 \mu \mathrm{l}$ of distilled water and $500 \mu \mathrm{l}$ of Folin's reagent were added into the solution. The samples were prepared in triplicates. The reaction mixtures were allowed to stand in the dark for 5 minutes. Then, $1.5 \mathrm{ml}$ sodium carbonate solution $(20 \% \mathrm{w} / \mathrm{v})$ was added, and the mixtures were incubated again in the dark at room temperature for 2 hours. Concurrently, the absorbance was measured at the wavelength of $760 \mathrm{~nm}$ against a reagent blank using a spectrophotometer (Secomam Prim, France). Different concentrations of gallic acid were used to prepare a calibration curve and the concentration of the gallic acid equivalent in the samples was calculated as follows:

$$
\text { " ТPC }=(C \times V) / M . "
$$

where TPC is total phenolic content in mg gallic acid equivalent per gram extract (GAE/g); $C$ is the concentration of gallic acid established from the calibration curve in $\mathrm{mg} / \mathrm{ml} ; V$ is the volume of the extract in $\mathrm{ml}$; and $M$ is the weight of the sample in $\mathrm{g}$.

\section{Determination of the total flavonoid content}

The total flavonoid content (TFC) was determined by using the aluminum chloride colourimetric method described by Wijekoon et al. (2011). Quercetin was used as a standard and the flavonoid content of the EEAE was expressed as $\mathrm{mg}$ of quercetin equivalent to per $\mathrm{g}$ of dried extract. The EEAE was dissolved in distilled water $(1 \mathrm{mg} / \mathrm{ml})$. Briefly, $1 \mathrm{ml}$ of test items (sample and standard) were transferred into the test tubes, and $4 \mathrm{ml}$ of distilled water were added. Then, $0.3 \mathrm{ml}$ of sodium nitrite solution $(5 \% \mathrm{w} / \mathrm{v})$ was added into the mixture and was allowed to stand for about 5 minutes. After that, $0.3 \mathrm{ml}$ of aluminium chloride solution $(10 \%$ 
w/v) was added and incubated for 1 minute before the addition of $2 \mathrm{ml}$ of sodium hydroxide (1 M). Subsequently, the reaction mixture was transferred into the cuvette, and the absorbance was measured at the wavelength of $420 \mathrm{~nm}$ against a reagent blank using a spectrophotometer (Secomam Prim, France). Different concentrations of quercetin were used to prepare a calibration curve and the concentration of quercetin equivalent in the samples was calculated as follows:

$$
\text { " } \mathrm{TFC}=(C \times V) / M . "
$$

where TFC is total flavonoid content in $\mathrm{mg}$ quercetin equivalent per gram extract $(\mathrm{QE} / \mathrm{g}) ; C$ is the concentration of quercetin established from the calibration curve in $\mathrm{mg} / \mathrm{ml}$; $V$ is the volume of the extract in $\mathrm{ml}$; and $M$ is the weight of the sample in $\mathrm{g}$.

\section{1,1-Diphenyl-2-picrylhydrazyl (DPPH) assay}

The DPPH assay was used to determine the free radical scavenging activity of the EEAE based on the method described by Ghasemzadeh et al. (2015). $2 \mathrm{ml}$ of test items $(0-200 \mu \mathrm{g} / \mathrm{ml}$ of sample and positive control) were transferred into the test tubes. Then, $2 \mathrm{ml}$ of DPPH solution $(0.1 \mathrm{mM})$ in methanol was added. These tests were prepared in triplicates. The solution was mixed well, wrapped in aluminium foil, and incubated for about 30 minutes at room temperature in the dark. After the incubation period, the reaction mixture was transferred into the cuvette, and the absorbance was measured at the wavelength of $517 \mathrm{~nm}$ against a reagent blank using a spectrophotometer (Secomam Prim, France). In this test, butylhydroxytoluene (BHT) was used as a positive control. The scavenging activity was calculated using the following formula:

$$
\begin{aligned}
" \mathrm{DPPH} \text { radical scavenging }(\%)= & (\text { control OD-sample OD } \\
& / \text { control OD }) \times 100 "
\end{aligned}
$$

\section{Ferric reducing antioxidant power (FRAP) assay}

The ferric reducing power of the extracts was determined by the method described by Benzie and Strain (1996) and Ojha et al. (2018). The FRAP reagent consisted of 10 volumes of $300 \mathrm{mM}$ acetate buffer ( $\mathrm{pH}=3.6), 1$ volume of $10 \mathrm{mM}$ 2,4,6-tripyridyl-Striazine (TPTZ) solution in $40 \mathrm{mM}$ hydrochloric acid $(\mathrm{HCl})$, and 1 volume of $20 \mathrm{mM}$ ferric chloride $(\mathrm{FeCl} 3)$ solution. The EEAE was dissolved in distilled water $(1 \mathrm{mg} / \mathrm{ml}) .50 \mu \mathrm{l}$ of sample/standard was pipetted into the cuvette, followed by $150 \mu \mathrm{l}$ of distilled water and $1.5 \mathrm{ml}$ of FRAP reagent. All tests were prepared in triplicates. The mixture was mixed well and incubated at room temperature in the dark for 30 minutes. Then, the absorbance of the mixtures was measured at the wavelength of $593 \mathrm{~nm}$ against a reagent blank using a spectrophotometer (Secomam Prim, France). The reagent blank comprised of the same reagents without the test items (sample/standard). A standard curve was prepared using various concentrations of Iron(II) sulphate heptahydrate ( $\left.\mathrm{FeSO}_{4} \cdot 7 \mathrm{H}_{2} \mathrm{O}\right)$. The FRAP activity was expressed as millimoles of Fe(II) per gram of sample, based on the calibration curve prepared with $\mathrm{FeSO}_{4} \cdot 7 \mathrm{H}_{2} \mathrm{O}$.

\section{In vitro antidiabetic activity of EEAE}

\section{$\alpha$-amylase inhibition assay}

The $\alpha$-amylase inhibition activity was determined by using previous methods (Md Norodin et al., 2018). In this test, a well-known amylase enzyme inhibitor, acarbose, was used as a positive control. Ten $\mu \mathrm{l}$ of $\operatorname{EEAE~}(100 \mu \mathrm{g} / \mathrm{ml})$ and acarbose $(100 \mu \mathrm{g} / \mathrm{ml})$ were transferred into the test and blank well in a 96well plate (Greiner Bio-one). Then, $50 \mu$ of $\alpha$-amylase enzyme solution $(4.0 \mathrm{U} / \mathrm{ml})$ and $40 \mu \mathrm{l}$ of distilled water were added into each well (a total $90 \mu \mathrm{l}$ of distilled water at blank wells) and the plate was incubated at $25^{\circ} \mathrm{C}$ for 5 minutes by using a thermo shaker incubator. After that, $100 \mu \mathrm{l}$ of starch $(0.5 \% \mathrm{w} / \mathrm{v})$ solution was added into each well and incubated again at $25^{\circ} \mathrm{C}$ for 7 minutes. After the incubation process, $100 \mu \mathrm{l}$ of DNS colour solution was added into each well in the dark and incubated at $85^{\circ} \mathrm{C}$ for 30 minutes. The plate was let to cool down to room temperature, and the absorbance was measured at $540 \mathrm{~nm}$. The inhibition of $\alpha$-amylase (\%) was calculated by using the following equation:

$$
\text { "Inhibition (\%) }=\frac{\left(A_{\text {Control }}-A_{\text {Sample }}\right)}{A_{\text {Control }}} \times 100 "
$$

where $A$ is the absorbance of a test mixture of a wavelength of $540 \mathrm{~nm}$.

\section{$\alpha$-glucosidase inhibition assay}

The $\alpha$-glucosidase inhibition activity was determined through the methods described by Md Norodin et al. (2018). $10 \mu \mathrm{l}$ of sample $(100 \mu \mathrm{g} / \mathrm{ml})$, acarbose $(100 \mu \mathrm{g} / \mathrm{ml})$, and quercetin $(100 \mu \mathrm{g} /$ $\mathrm{ml})$ (positive control) were transferred into a 96-well plate. $20 \mu \mathrm{l}$ of

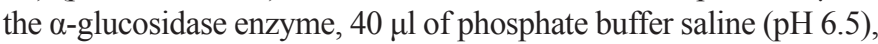
and $20 \mu \mathrm{l}$ of distilled water were added into each well and incubated at $37^{\circ} \mathrm{C}$ for 10 minutes by using a thermo shaker incubator. Next, $10 \mu \mathrm{l}$ of pNPG was added into all wells in the dark. Then, the plate was incubated again at $37^{\circ} \mathrm{C}$ for 30 minutes, and the absorbance was read at $405 \mathrm{~nm}$ (BMG, FLUOstar Omega). The inhibition of $\alpha$-glucosidase (\%) was calculated using the following equation:

$$
\text { “Inhibition }(\%)=\frac{\left(\mathrm{A}_{\text {Control }}-\mathrm{A}_{\text {Sample }}\right)}{\mathrm{A}_{\text {Control }}} \times 100 "
$$

where $\mathrm{A}$ is the absorbance of a test mixture of a wavelength of $405 \mathrm{~nm}$.

\section{In vivo antidiabetic activity of EEAE}

\section{Experimental animal}

Forty-two male Sprague Dawley rats (SD) weighing 200-250 g were purchased from the Animal Research and Service Centre (ARASC), USM, and were placed in a temperaturecontrolled room at $23 \pm 1{ }^{\circ} \mathrm{C}$ and a 12-hour dark/ light cycle. All the animals were treated according to the guidelines of animal care from ARASC, USM, and the protocols were approved by the Institutional Animal Care and Use Committee (IACUC; USM/ Animal Ethics Approval/2016(760)).

\section{Induction of type 2 DM rat model}

After 1 week of the adaptation period, the rats were randomly divided into two groups: the control group $(n=7)$ and high-fat diet (HFD) group $(n=35)$. Control group was given a standard diet, while HFD group was given high fat diet pellet consisted of $32 \%$ animal fat prepared based on the method described by Nursyuhana et al. (2016). Rats were fed according to their corresponding diets for six weeks to induce obesity. Consequently, the rats with a body mass index of more than 0.68 $\mathrm{g} / \mathrm{cm}^{2}$ were considered obese (Novelli et al., 2007). 
At the end of week six, the HFD-feeding rats were divided into two groups, healthy obese $(n=7)$ and diabetic obese (Obese-DM, $n=28$ ). The induction of type $2 \mathrm{DM}$ was carried out on the Obese-DM group by using a single low dose of STZ (35 $\mathrm{mg} / \mathrm{kg}$ ). Before the injection, the rats were fasted overnight and were given a single intraperitoneal injection of STZ in a citrate buffer ( $\mathrm{pH} 4.5)$, while the rats in the standard group and the obese group received just the citrate buffer. After the induction, the blood glucose level was measured on day seven to confirm the diabetic condition in the rats. The level of blood glucose more than 11.1 $\mathrm{mmol} / \mathrm{l}$ was included in this study. Overall, the groups were assigned as Group 1: normal; Group 2: obese; Group 3: untreated DM; Group 4: DM treated with $250 \mathrm{mg} / \mathrm{kg}$ of metformin; Group 5: DM treated with $500 \mathrm{mg} / \mathrm{kg}$ of EEAE; and Group 6: DM treated with $1000 \mathrm{mg} / \mathrm{kg}$ of EEAE, respectively. The normal (Group 1) and obese (Group 2) groups acted as standard diet control and obese control without DM, respectively. All rats were treated equally for 6 weeks and the weekly fasting blood glucose level was measured throughout the study period by using portable AccuCheck Advantage glucometer (One Touch Ultra). At the end of the study, all rats were euthanized, and the blood was collected by a cardiac puncture, and the samples were sent to a local laboratory service for the measurement of biochemical parameters by using an Architect chemistry analyser (Abott Ci 8200).

\section{Statistical analysis}

All measurements were carried out in triplicate $(n=$ $3)$. All the results were presented in the form of mean \pm standard deviation (SD). Data for $\alpha$-amylase was statistically analyzed by Student's $t$-test, while data for $\alpha$-glucosidase and biochemical parameters were analyzed by one-way analysis of variance (ANOVA). Random blood glucose level and body weight were analyzed by two-way ANOVA by using GraphPad Prism version 8.0.

\section{RESULTS}

Total phenolic, total flavonoid content, and antioxidant activity of E. elatior extract

TPC of the EEAE was expressed in $\mathrm{mg}$ GAE/g extract by using the gallic acid standard curve $\left(R^{2}=0.9913\right)$, and the TFC was expressed in $\mathrm{mg}$ QE/g extract by using the quercetin standard curve $\left(R^{2}=0.9999\right)$. Meanwhile, the antioxidant activity was evaluated by the DPPH and FRAP assays through a synthetic antioxidant BHT and ascorbic acid as a controlled drug, respectively. The results demonstrate that the EEAE exhibited a high amount of total phenolic (39.06 $\pm 1.59 \mathrm{mg} \mathrm{GAE} / \mathrm{g})$ and total flavonoid $(39.00 \pm 2.42 \mathrm{mg} \mathrm{QE} / \mathrm{g}$ extract) contents. The percentage of the DPPH inhibition at $200 \mu \mathrm{g} / \mathrm{ml}$ was $88.7 \%$ for EEAE and $96.9 \%$ for BHT, with the $\mathrm{IC}_{50}$ value of $47.55 \pm 7.88 \mu \mathrm{g} /$ $\mathrm{ml}(n=3)$ and $18.45 \pm 2.52 \mu \mathrm{g} / \mathrm{ml}(n=3)$, respectively. For the FRAP assay, the reducing power of the extract was determined as the reduction of $\mathrm{Fe}^{3+}-\mathrm{TPTZ}$ complex to $\mathrm{Fe}^{2+}-\mathrm{TPTZ}$. The intensity of the reduced form was measured spectrophotometrically in comparison with the standard curve of $\mathrm{Fe}^{2+}\left(R^{2}=0.9999\right)$. The FRAP value of the EEAE obtained was $0.627 \pm 0.02 \mathrm{mM} \mathrm{Fe}^{2+}$ equivalent/g of extract $(n=3)$, while the FRAP value for ascorbic acid was $10.77 \pm 0.42 \mathrm{mM} \mathrm{Fe}^{2+}$ equivalent/g of ascorbic acid. The overall values are summarized in Table 1 .

\section{In vitro $\alpha$-amylase and $\alpha$-glucosidase inhibitory activities}

Preliminary screening of EEAE for in vitro antidiabetic activity was carried out at $100 \mu \mathrm{g} / \mathrm{ml}$ extract. The inhibitory activity against the $\alpha$-amylase and the $\alpha$-glucosidase enzymes are shown in Figure 1a and b. In this study, acarbose, an established inhibitor for $\alpha$-amylase, and quercetin, a well-known compound to control postprandial hyperglycemia, were used as the positive control drugs. Acarbose blocks the pancreatic $\alpha$-amylase and membrane-bound $\alpha$-glucosidase, reducing the rate of carbohydrate digestion. Meanwhile, quercetin was used as a positive control for the $\alpha$-glucosidase assay based on reports claiming that the phenolic compounds have a stronger inhibitory activity on $\alpha$-glucosidase compared to acarbose (Indrianingsih et al., 2015) As shown in Figure 1a, the EEAE had a strong inhibitory activity against the $\alpha$-amylase enzyme, and no significant difference was observed when compared with the positive control, acarbose. The results also demonstrate that the EEAE exhibited $99.7 \pm 4.97 \%$ of enzyme inhibition, while $100 \pm 1.92 \%$ inhibition was achieved for acarbose. For the $\alpha$-glucosidase assay, the EEAE showed moderate inhibition (52.39 $\pm 2.12 \%)$ and was statistically significant with the quercetin compound $(97.62 \pm 1.23 \%)$ that was used as a positive control $(p<0.001)$. Note that in this test, acarbose $(10.62$ $\pm 11.03 \%$ ) displayed a weak inhibition for $\alpha$-glucosidase enzyme, and the inhibitory activity of EEAE was significantly higher than acarbose but lower than quercetin (Fig. 1b).

\section{In vivo antihyperglycemic activity of EEAE and its effect on body weight}

The efficacy of the study of EEAE was evaluated in the SD rats induced type $2 \mathrm{DM}$ model. Figure 2 shows that the EEAE significantly decreased the fasting blood glucose level in a dose-dependent manner with a blood glucose level of $13.77 \pm$ $3.59 \mathrm{mmol} / 1$ for $500 \mathrm{mg} / \mathrm{kg}$ of EEAE and $9.63 \pm 2.47 \mathrm{mmol} / \mathrm{l}$ for $1,000 \mathrm{mg} / \mathrm{kg}$ of EEAE when compared to untreated DM $(22.43 \pm$ $1.30 \mathrm{mmol} / \mathrm{l})$ after 6 weeks of the experimental period $(p<0.001)$. Interestingly, no significant difference in blood glucose level was observed between $1,000 \mathrm{mg} / \mathrm{kg}$ EEAE and control drug metformin.

As shown in Figure 3, the near average level of body weight was achieved for metformin and $1,000 \mathrm{mg} / \mathrm{kg}$ of EEAE at the end of the study period. Note that the body weight dropped after DM induction and remained constant starting from week 3 of the treatment. On the other hand, there was a pattern of consistent weight loss in untreated DM throughout the study period, but

Table 1. TPC, TPC, DPPH scavenging activity, and FRAP of E. elatior flower aqueous extract. Values are means $\pm \operatorname{SD}(n=3)$.

\begin{tabular}{|c|c|c|c|c|c|}
\hline \multirow{2}{*}{ Samples } & \multirow{2}{*}{ TPC (mg GAE/g extract) } & \multirow{2}{*}{ TFC (mg QE/g extract) } & \multicolumn{2}{|c|}{ DPPH assay } & \multirow{2}{*}{ FRAP assay $\left(\mathrm{mM} \mathrm{FE} \mathrm{FE}^{2+} / \mathrm{mg}\right.$ extract) } \\
\hline & & & $\%$ inhibition & $\left(\mathrm{IC}_{50} \mu \mathrm{g} / \mathrm{ml}\right)$ & \\
\hline EEAE & $39.06 \pm 1.59$ & $39.00 \pm 2.42$ & 88.3 & $47.55 \pm 7.8$ & $0.627 \pm 0.02$ \\
\hline
\end{tabular}


a)

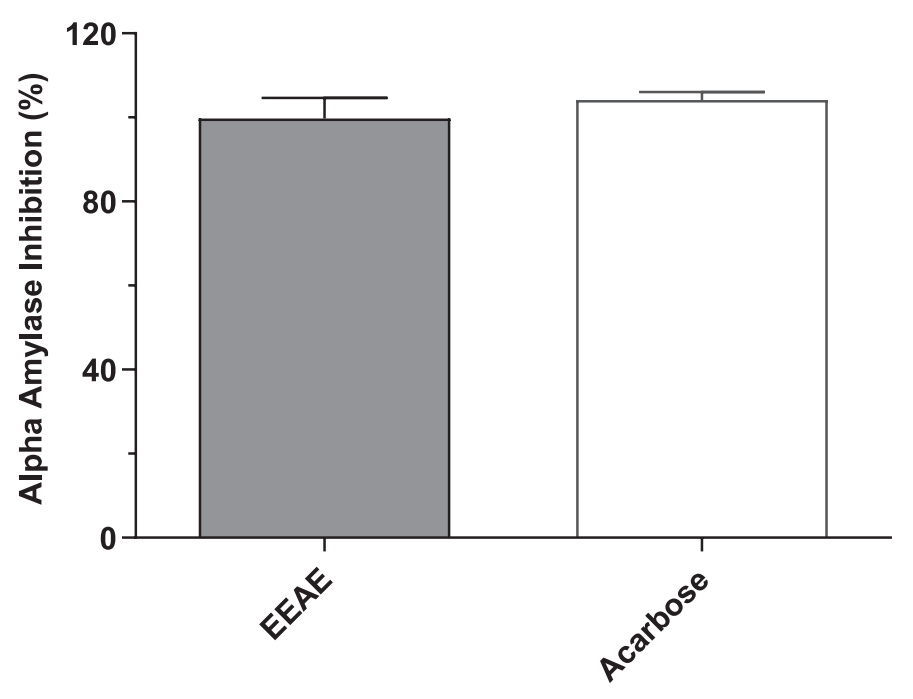

b)

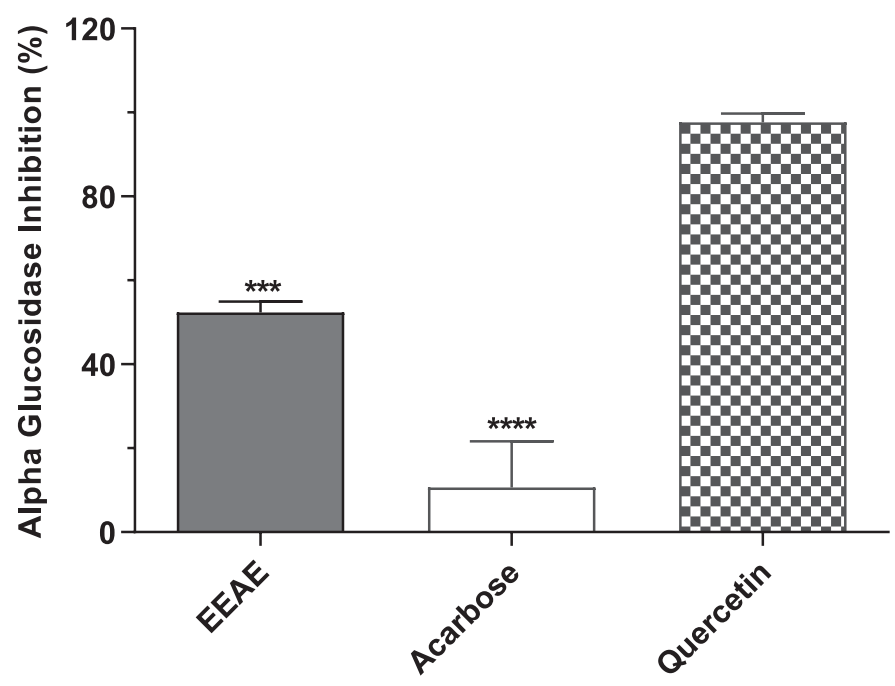

Figure 1. Inhibitory activity of EEAE against (a) $\alpha$-amylase and (b) $\alpha$-glucosidase enzyme at a concentration of $100 \mu \mathrm{g} / \mathrm{ml}$. Values are expressed as mean inhibition $(\%) \pm$ SD of triplicate measurements from three independent experiments ${ }^{* * * *} p<$ 0.001 and ${ }^{* * * *} p<0.0001$ when compared to quercetin).

no significant difference was observed when compared with all treatment groups.

\section{The effect of EEAE on biochemical profiling}

Biochemical parameters were evaluated at the end of the study to determine the effect of the extract on biochemical profiles related to DM. The findings revealed that EEAE improved hyperlipidemia in the type $2 \mathrm{DM}$ rat model. Figure 4 shows that EEAE significantly reduced the elevated total cholesterol $(p<$ 0.01 ), triglycerides $(p<0.001)$, and low-density lipoprotein (LDL; $p<0.01$ ) levels when compared with untreated DM. However, no significant difference was detected for high-density lipoprotein
(HDL) levels. The EEAE treatment also significantly decreased the plasma creatinine level $(p<0.01)$, alanine aminotransferase (ALT) $(p<0.01)$, and alkaline phosphatase (ALP) $(p<0.001)$ when compared with untreated DM, and no significant difference was observed for urea and aspartate aminotransferase (AST) levels (Table 2).

\section{DISCUSSION}

Diabetes is characterized by high blood glucose levels, which lead to severe complications if left untreated for a long time. The prevalence of type $2 \mathrm{DM}$ was increasing worldwide and accounted for approximately $95 \%$ of all diabetes cases (International Diabetes Federation, 2017; Zheng et al., 2018). Obesity is the most common risk factor for the development of type $2 \mathrm{DM}$, which leads to the elevation of serum triglycerides, hypertension, and insulin resistance (Gheibi et al., 2017). Moreover, various complications are also related to the disease, which include retinopathy, nephropathy, and neuropathy, as well as atherosclerosis and coronary heart disease.

Nowadays, the management of diabetes without any severe side effects remains a challenge as most of the glucoselowering drugs may come with side effects, including severe hypoglycemia, lactic acidosis, idiosyncratic liver cell injury, digestive discomfort, headache, and dizziness (Prabhakar and Doble, 2011). Therefore, medicinal plants with potential antidiabetic properties are sought after in search of safer and cost-effective antidiabetic drugs. This study has revealed that $E$. elatior flower exhibited an in vitro inhibitory activity for both the $\alpha$-amylase and the $\alpha$-glucosidase enzymes. Theoretically, a rise in blood glucose levels, which causes hyperglycemia conditions in type $2 \mathrm{DM}$, occurs due to the hydrolysis of starch by pancreatic $\alpha$-amylase and uptake of glucose by intestinal $\alpha$-glucosidases (Kwon et al., 2006). The inhibition of these enzymes is recognized as a therapeutic target for modulation of postprandial hyperglycemia. Therefore, it is suggested to be a useful approach for the management and prevention of type 2 diabetes (Lordan et al., 2013; Nair et al., 2013; Oboh, 2013).

The efficacy of this extract was further evaluated in the in vivo study by using the type 2 DM rat model. In this study, we used a combination of HFD feeding to induce obesity and a low dose of STZ that caused minimal dysfunction of the $\beta$-cells in the pancreas for the development of type $2 \mathrm{DM}$. It was proposed that obese animals tend to develop insulin resistance and exhibited metabolic characteristics as well as developed a natural history of disease progression similar to those seen in humans with type 2 DM (Fang et al., 2019). Moreover, this model develops a stable and long-lasting hyperglycemia which becomes a valuable research tool in a diabetic study (Guo et al., 2018). Consistent with in vitro inhibition, the EEAE was shown to decrease fasting blood glucose levels in a dose-dependent manner in the in vivo study. The results clearly indicated that EEAE was able to regulate a positive outcome toward reducing hyperglycemia where no significant difference was observed when compared with control drug, metformin, after 6 weeks.

Concurrently, the body weight was reduced to near normal in metformin and EEAE at a dose of $1000 \mathrm{mg} / \mathrm{kg}$ groups, therefore, indicating that the EEAE at this dose was able to reduce obesity when compared with the obese control group at the end 


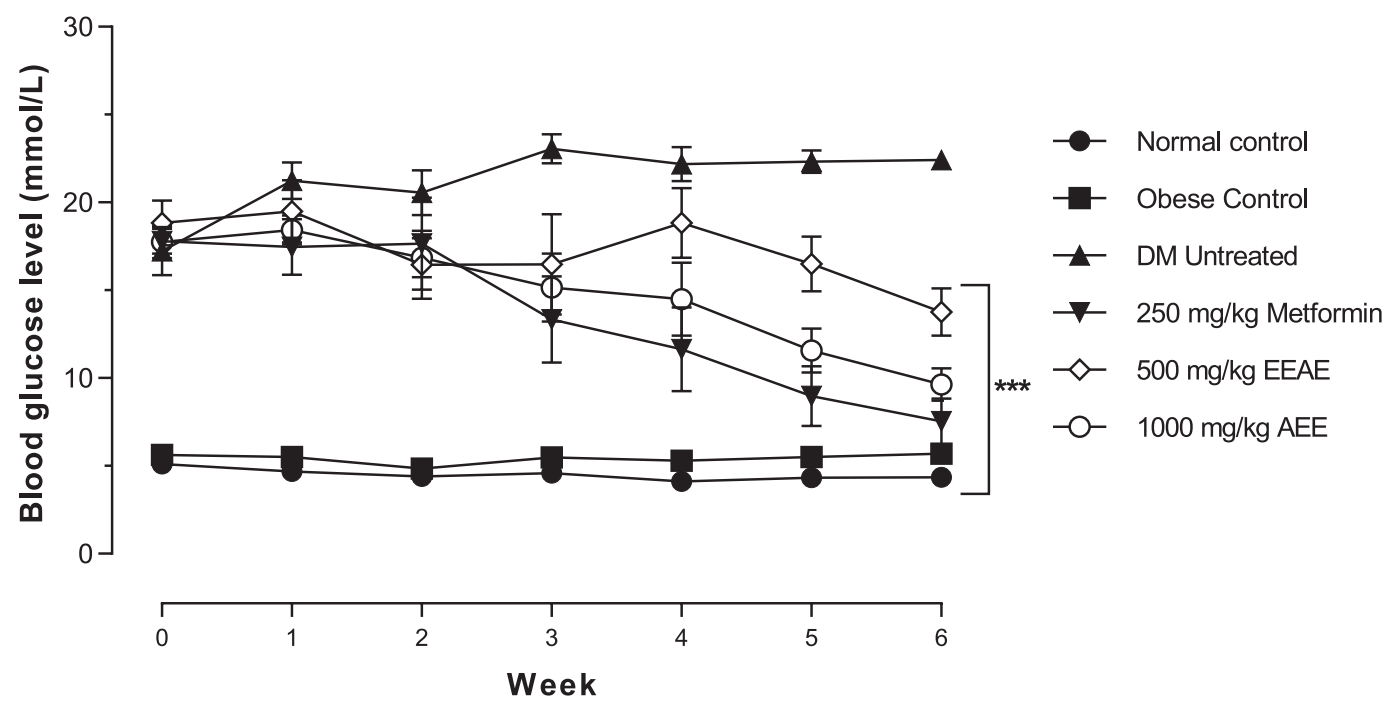

Figure 2. The effects of the different treatments on fasting blood glucose levels in experimental rats $(* * * p<0.001$, main effects when compared to untreated diabetic rats).

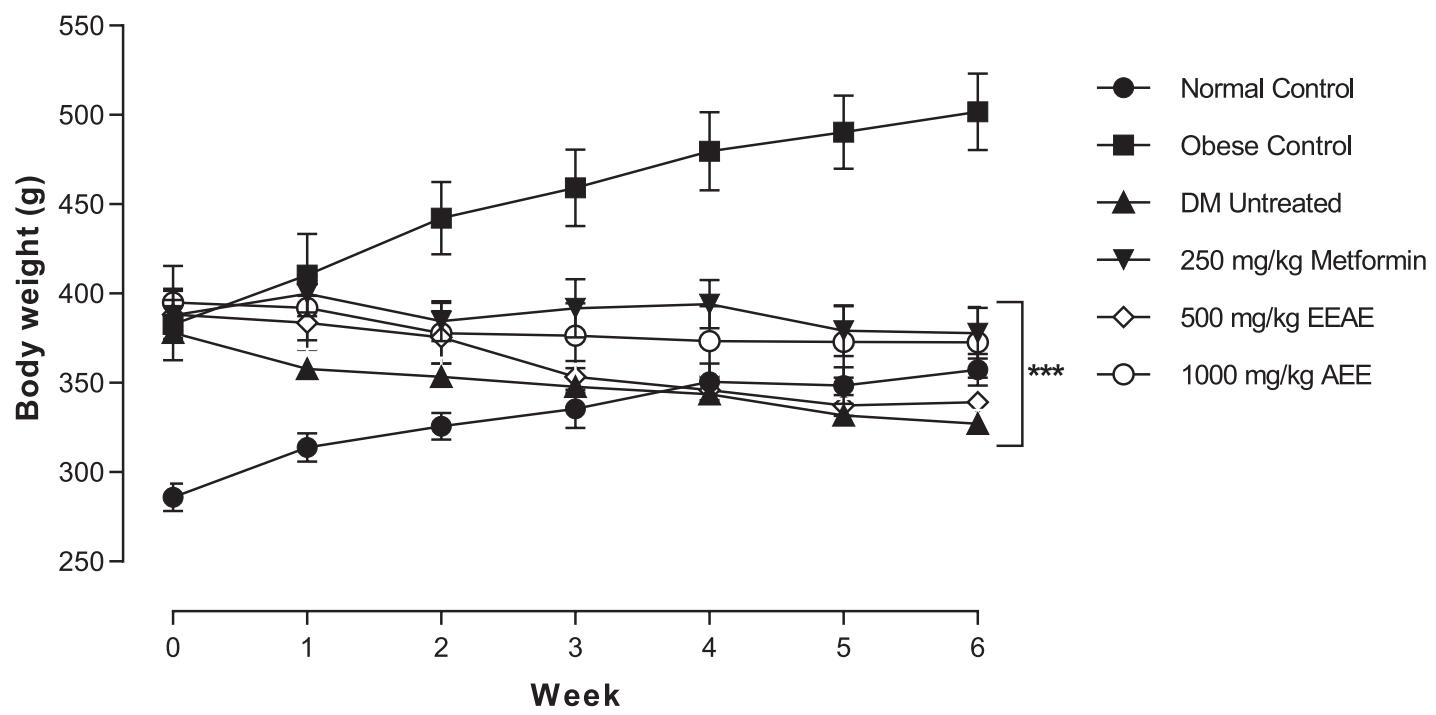

Figure 3. The effects of the different treatments on body weight in experimental rats throughout the study period $\left(^{* * *} p<0.001\right.$, main effects when compared to the obese control group).

of the study period. There was a pattern of weight loss which occurred in untreated DM, but no significant difference in body weight was detected in all the treatment groups after six weeks of treatment. This could be because there was no massive weight loss in type $2 \mathrm{DM}$ rats used this model. In contrast to type $1 \mathrm{DM}$, a clear and sudden weight loss is not observed as in type 2 diabetes. However, significant weight loss was observed with prolonged disease exposure (Skovsø, 2014).

Type $2 \mathrm{DM}$ is always associated with changes in the lipid profile, hepatic enzyme, and kidney function (Khadke et al., 2019). In this study, E. elatior extract was observed to significantly lower the elevation of total cholesterol, triglycerides, and LDL levels. However, the mechanism involved in this effect was not evaluated in this study. A systematic review on various herbal extracts suggested that antihyperlipidemia activity was related to several mechanisms, such as modification of lipid peroxidation by reducing glutathione peroxidase activity, increased excretion of faecal bile acids, upregulation of LDL receptor as well as the presence of bioactive compound high in antioxidant properties (Rouhi et al., 2015). At the molecular level, a decreased expression of adipogenic factors, such as peroxisome proliferators activated-receptor-gamma and sterol regulatory element-binding protein, were also suggested as a possible mechanism involved in hypolipidemic effect of herbal plant in vitro (Vijayakumar et al., 2010). In this study, the levels of serum creatinine, ALT, and ALP were also significantly reduced when compared to the untreated ones, which suggested that this extract exhibited a hepatoprotective effect and improved renal function in type 2 DM rats. Controlled hyperglycemic levels could be one of the possible reasons for the improvement of biochemical parameters in all treatment groups. 

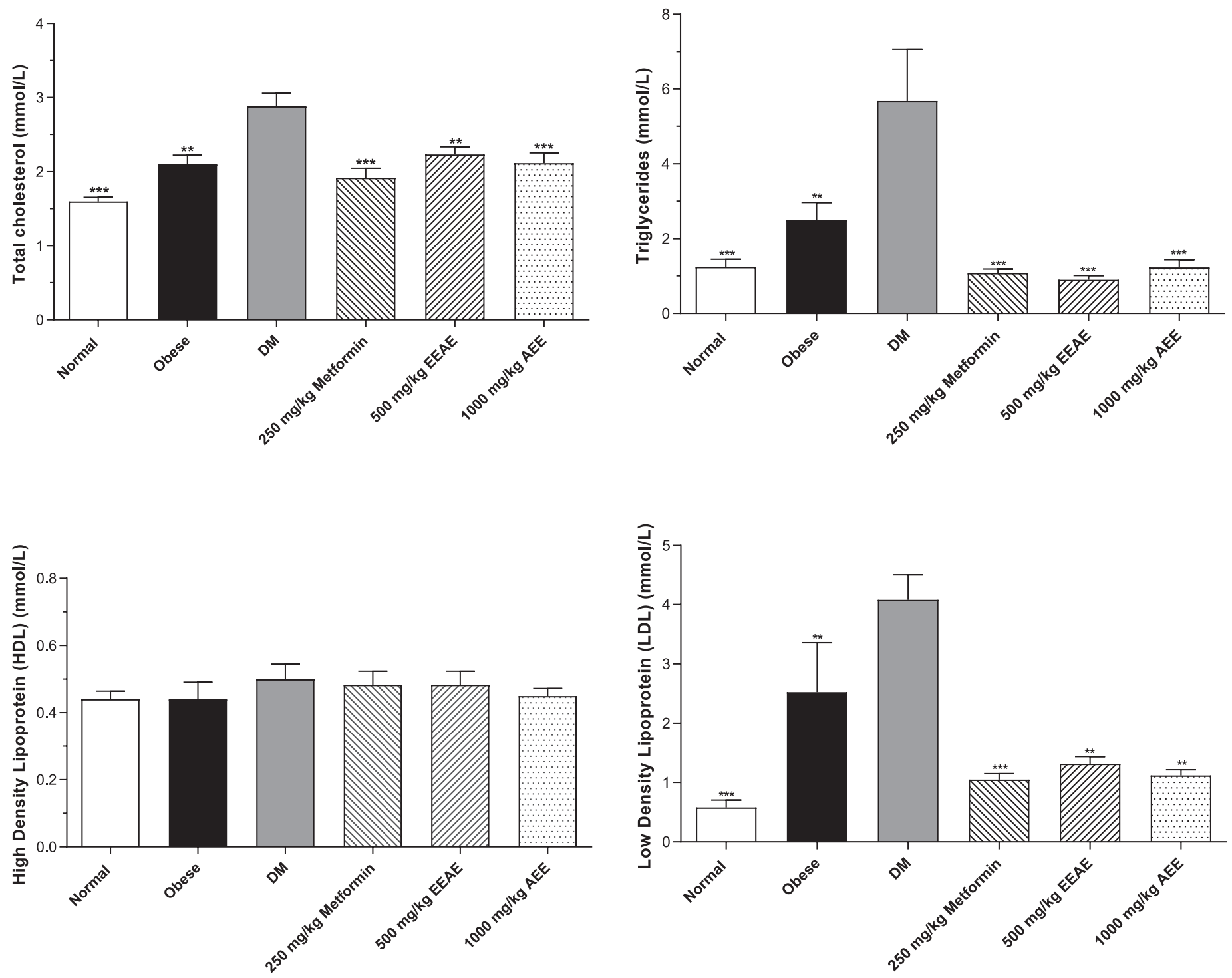

Figure 4. Lipid profile for all treatment groups after six weeks. Data were analysed by using one-way ANOVA $\left({ }^{* *} p<0.01\right.$ and ${ }^{* * *} p<0.001$ when compared to untreated DM).

Table 2. Biochemical parameters for particular groups after 6 weeks. Values are mean \pm SD of seven animals in each group. Data were analysed by using one-way ANOVA, respectively $\left(" p<0.05,{ }^{* *} p<0.01\right.$ and ${ }^{* * *} p<0.001$ when compared to the untreated DM group).

\begin{tabular}{|c|c|c|c|c|c|c|}
\hline Biochemical parameters & Normal & Obese & Diabetes Mellitus & $250 \mathrm{mg} / \mathrm{kg}$ metformin & $500 \mathrm{mg} / \mathrm{kg}$ EEAE & $1000 \mathrm{mg} / \mathrm{kg} \mathrm{EEAE}$ \\
\hline Urea & $7.36 \pm 0.27$ & $6.46 \pm 0.28^{* * *}$ & $9.04 \pm 0.53$ & $7.09 \pm 0.53^{*}$ & $8.74 \pm 0.59$ & $8.31 \pm 0.43$ \\
\hline Creatinine & $47.03 \pm 1.34^{* * *}$ & $52.25 \pm 1.87^{* * * *}$ & $69.07 \pm 1.35$ & $54.67 \pm 1.61^{* * *}$ & $60.02 \pm 2.11^{* *}$ & $57.44 \pm 1.72^{* * *}$ \\
\hline SGOT/AST & $123.6 \pm 7.87$ & $145.0 \pm 9.40$ & $151.4 \pm 21.80$ & $128.4 \pm 12.69$ & $107.3 \pm 17.83$ & $116.1 \pm 8.63$ \\
\hline SGPT/ALT & $68.56 \pm 3.02^{* *}$ & $70.63 \pm 7.14^{* *}$ & $108.6 \pm 12.65$ & $75.25 \pm 5.65^{*}$ & $66.13 \pm 8.35^{* *}$ & $61.75 \pm 5.9^{* * * *}$ \\
\hline ALP & $269.0 \pm 14.95^{* * *}$ & $454.5 \pm 34.22^{* * * *}$ & $1459 \pm 98.38$ & $507.9 \pm 130.8^{* * * *}$ & $579.3 \pm 106.5^{* * * *}$ & $403.3 \pm 84.38^{* * * *}$ \\
\hline
\end{tabular}

The findings suggested that the antidiabetic activity could be due to the high antioxidant properties and the presence of active compounds in the extract. A study by Omari et al. (2019) on in vitro antioxidant and antidiabetic activities of Aristolochia longa extracts revealed that the presence of phenols and flavonoids in the extract contributed to its multiple biological properties. In another study, they claimed that the phenolic compounds could regulate the glucose uptake by inhibiting carbohydrate digestion and absorption (Shobana et al., 2009). Likewise, the presence of flavonoids may also account for the inhibitory activity observed. Indeed, flavonoids are known to possess high inhibitory potential toward in vitro and in vivo studies (Fang et al., 2019; Kidane et al., 2018; Li et al., 2018). Notably, some researchers have indicated that there is a positive correlation between polyphenolic composition and the ability of the extract to inhibit both $\alpha$-amylase and $\alpha$-glucosidase enzymes (Ramkumar et al., 2010). By 
inhibiting those enzymes concerning its antioxidant activity, the hyperglycemia as well as biochemical changes toward diabetes disease are improving.

\section{CONCLUSION}

This study revealed that E. elatior flower's extract had the ability to inhibit both $\alpha$-amylase and $\alpha$-glucosidase enzyme in vitro and possessed antihyperglycemic activity in the type 2 $\mathrm{DM}$ rat model. A potent antioxidant capacity with a high content of TPC and TFC in the extract may have a great influence on its antidiabetic effect. The findings from this study provide the scientific data on potential antioxidant compounds present in the extract as well as the efficacy assessment toward the hypoglycemic effect of the EEAE. Thus, E. elatior can be an ideal natural source of antioxidants and antidiabetic compounds that can be used for the prevention or treatment of DM. Furthermore, research should be conducted to investigate the bioactive compounds of antidiabetic activity.

\section{ACKNOWLEDGMENT}

The authors thank the HRGS research grant, Universiti Sains Malaysia (USM), for their financial support, and the Animal Research and Service Centre (ARASC), USM, and Central Research Laboratory (CRL), USM, for their technical support.

\section{CONFLICT OF INTEREST}

The authors declare that they have no conflict of interest.

\section{FUNDING SOURCE}

This study was funded by the HRGS research grant, USM:304.PPSK.6150169.K123.

\section{REFERENCES}

Annegowda HV, Bhat R, Min-Tze L, Karim AA, Mansor SM. Influence of sonication treatments and extraction solvents on the phenolics and antioxidants in star fruits. J Food Sci Technol, 2012; 49(4):510-4.

Benzie IFF, Strain JJ. The ferric reducing ability of plasma (FRAP) as a measure of "Antioxidant Power": the FRAP Assay. Anal Biochem, 1996; 239(1):70-6.

Chan EWC, Lim YY, Omar M. Antioxidant and antibacterial activity of leaves of Etlingera species (Zingiberaceae) in Peninsular Malaysia. Food Chem, 2007; 104(4):1586-93.

Chan Eric WC, Lim YY, Wong SK. Phytochemistry and pharmacological properties of Etlingera elatior: a review. Pharmacogn J, 2011; 3(22):6-10.

Evans JL, Goldfine ID, Maddux BA, Grodsky GM. Oxidative stress and stress-activated signaling pathways: a unifying hypothesis of type 2 diabetes. Endocr Rev, 2002; 23(5):599-622.

Fang J-Y, Lin C-H, Huang T-H, Chuang S-Y. In vivo rodent models of type 2 diabetes and their usefulness for evaluating flavonoid bioactivity. Nutrients, 2019; 11(3):530.

Ghasemzadeh A, Jaafar HZE, Rahmat A, Ashkani S. Secondary metabolites constituents and antioxidant, anticancer and antibacterial activities of Etlingera elatior (Jack) R.M.Sm grown in different locations of Malaysia. BMC Complement Altern Med, 2015; 15(1):1-10.

Gheibi S, Kashfi K, Ghasemi AA practical guide for induction of type-2 diabetes in rat: Incorporating a high-fat diet and streptozotocin. Biomed Pharmacother, 2017; 95(24):605-13.

Guo X, Wang Y, Wang K, Ji B, Zhou F. Stability of a type 2 diabetes rat model induced by high-fat diet feeding with low-dose streptozotocin injection. J Zhejiang Univ Sci B, 2018; 19(7):559-69.
Habsah M, Ali AM, Lajis NH, Sukari MA, Yap YH, Kikuzaki H, Nakatani N. Antitumour-promoting and cytotoxic constituents of Etlingera elatior. Malaysian J Med Sci, 2005; 12(1):6-12.

Haleagrahara N, Jackie T, Chakravarthi S, Rao M. Protective effect of Etlingera elatior ( torch ginger ) extract on lead acetate-induced hepatotoxicity in rats. J Toxicol Sci, 2010; 35(5):663-71.

Hueh Zan C, Rahmat A, Akim M, Banu Mohd Alitheen N, Othman F, Ee Cheng Lian G. Anti-proliferative effects of pandan leaves (Pandanus amarylfolius), kantan flower (Etlingera elatior) and turmeric leaves (Curcuma longa). Nutr Food Sci, 2011; 41(4):238-41.

Indrianingsih $\mathrm{AW}$, Tachibana $\mathrm{S}$, Itoh $\mathrm{K}$. In vitro evaluation of antioxidant and $\alpha$-glucosidase inhibitory assay of several tropical and subtropical plants. Procedia Environ Sci, 2015; 28:639-48.

Interantional Diabetes Federation. Idf Diabetes Atlas, 2017 Available via http://www.diabetesatlas.org/

Jackie T, Haleagrahara N, Chakravarthi S. Antioxidant effects of Etlingera elatior flower extract against lead acetate - induced perturbations in free radical scavenging enzymes and lipid peroxidation in rats. BMC Res Notes, 2011; 4(1):67.

Jeevani Osadee Wijekoon MM, Karimand AA, Bhat R. Evaluation of nutritional quality of torch ginger (Etlingera elatior Jack.) inflorescence. Int Food Res J, 2011; 18(4):1415-20.

Khadke SP, Kuvalekar AA, Harsulkar AM, Mantri N. High energy intake induced overexpression of transcription factors and its regulatory genes involved in acceleration of hepatic lipogenesis: a rat model for type 2 diabetes. Biomedicines, 2019; 7(4).

Kidane Y, Bokrezion T, Mebrahtu J, Mehari M, Gebreab YB, Fessehaye N, Achila OO. In vitro inhibition of $\alpha$-amylase and $\alpha$-glucosidase by extracts from Psiadia punctulata and Meriandra bengalensis. Evid Based Complement Altern Med, 2018.

Kwon Y, Apostolidis E, Shetty K. Inhibitory potential of wine and tea against a-amylase and a-glucosidase for management of hyperglycemia linked type 2 diabetes. J Food Biochem, 2008; 32:15-31.

Lachumy SJT, Sasidharan S, Sumathy V,Zuraini Z. Pharmacological activity, phytochemical analysis and toxicity of methanol extract of Etlingera elatior (torch ginger) flowers. Asian Pacific J Trop Med, 2010.

Lazo-de-la-Vega-Monroy, M.-L., \& Fernndez-Mej, C. Oxidative Stress in Diabetes Mellitus and the Role Of Vitamins with Antioxidant Actions. Licens. InTech., 2013, 209-232.

Li K, Yao F, Xue Q, Fan H, Yang L, Li X, Sun L, Liu Y. Inhibitory effects against $\alpha$-glucosidase and $\alpha$-amylase of the flavonoids-rich extract from Scutellaria baicalensis shoots and interpretation of structure-activity relationship of its eight flavonoids by a refined assign-score method. Chem Central J, 2018; 12(1):1-11.

Lordan S, Smyth TJ, Soler-Vila A, Stanton C, Paul Ross R. The $\alpha$-amylase and $\alpha$-glucosidase inhibitory effects of Irish seaweed extracts. Food Chem, 2013; 141(3):2170-6.

Md Norodin NS, Md Salleh L, Yusof N, Mustapha NM, Kamarulzaman F, Zahari MAM, Bakeri NA. Inhibitory effects of swietenia mahagoni seeds extract on A-glucosidase and A-amylase. Int J Eng Transact Appl, 2018; 31(8):1308-17.

Nair SS, Kavrekar V, Mishra A. In vitro studies on alpha amylase and alpha glucosidase inhibitory activities of selected plant extracts. Eur J Exp Biol, 2013; 3(1):128-32.

Nor Asiah MN, Afifah A, Liza N, Hidayah AB, Nizam WA Aqueous extract of Etlingera elatior flowers improved blood glucose control, kidney function and histology of streptozotocin-induced diabetic rat. J Sustain Sci Manag, 2019; 14(3):80-91.

Novelli EL, Diniz YS, Galhardi CM, Ebaid GM, Rodrigues HG, Mani F, Fernandes AA, Cicogna AC, Novelli Filho JL. Anthropometrical parameters and markers of obesity in rats. Lab Anim, 2007; 111-9.

Nursyuhana R, Ramli NS, Safuan S, Noordin L, Ahmad WANW. Histopathological alterations in organ structures of induced-obese rats feed with high-fat diet. Ann Microsc, 2016; 15:38-48. 
Oboh G. Inhibition of -amylase and -glucosidase activities by ethanolic extract of Amaranthus cruentus leaf as affected by blanching. Afr J Pharm Pharmacol, 2013; 7(17),

Ojha S, Raj A, Roy A, Roy S. Extraction of total phenolics, flavonoids and tannins from paederia foetida 1 . Leaves and their relation with antioxidant activity. Pharmacogn J, 2018; 10(3):541-7.

Omari NEl, Sayah K, Fettach S, Blidi OEl, Bouyahya A, Faouzi MEA, Kamal R, Barkiyou M. Evaluation of in vitro antioxidant and antidiabetic activities of Aristolochia longa extracts. Evid Based Complement Altern Med, 2019; 2019:9.

Patel C, Satyanand T, Nirmala H, Jaya Y, Sachchidanand P, Satya PS, Pandey A, Darshan SK, Pratap S. Antioxidant activity of herbal plants: a recent review. J Drug Discov Ther, 2013; 1(8):1-8.

Prabhakar PK, Doble M. Mechanism of action of natural products used in the treatment of diabetes mellitus. Chin J Integr Med, 2011; 17(8):563-74.

Ramasamy S, Mazlan NA, Ramli NA, Rasidi WNA, Manickam S. Bioactivity and stability studies of anthocyanin-containing extracts from Garcinia mangostana L. and Etlingera elatior Jack. Sains Malaysiana. Chem Cent J, 2016; 45(4):559-65.

Ramkumar KM, Thayumanavan B, Palvannan T, Rajaguru P. Inhibitory effect of gymnema montanum leaves on $\alpha$-glucosidase activity and $\alpha$-amylase activity and their relationship withpolyphenolic content. Med Chem Res, 2010; 19(8):948-61.

Rouhi-Boroujeni H, Rouhi-Boroujeni H, Heidarian E, Mohammadizadeh F, Rafieian-Kopaei, M. Herbs with anti-lipid effects and their interactions with statins as a chemical antihyperlipidemia group drugs: a systematic review. ARYA Atherosclerosis, 2015; 11(4):244-51.

Shobana S, Sreerama YN, Malleshi NG. Composition and enzyme inhibitory properties of finger millet (Eleusine coracana L.) seed coat phenolics: mode of inhibition of $\alpha$-glucosidase and pancreatic amylase. Food Chem, 2009; 115(4):1268-73.

Skovsø S. Modeling type 2 diabetes in rats using high fat diet and streptozotocin. J Diabet Investig, 2014; 5(4):349-58.

Srey C, Sontimuang C, Thengyai S, Ovatlarnporn C, Puttarak P. Research article activities of Etlingera elatior rhizome. J Chem Pharm Res, 2014; 6(12):885-91.
Tiwari BK, Pandey KB, Abidi AB, Rizvi SI. Markers of oxidative stress during diabetes mellitus. J Biomarkers, 2013:1-8.

V.L, S., \& Rossi, J. A. Colorimetry of total phenolics with phosphomolybdic-phosphotungstic acid reagent. Am J Enol Veticulture, 1965; 16(3):144-58.

Vijayakumar MV, Pandey V, Mishra GC, Bhat MK. Hypolipidemic effect of fenugreek seeds is mediated through inhibition of fat accumulation and upregulation of LDL receptor. Obesity, 2010 18(4):667-74; https://doi.org/10.1038/oby.2009.337

Wai Mai C, Yi Wong S, Ling Tan E, Katyayani Balijepalli M, Rao Pichika M. Antiproliferative and apoptotic studies of the standardised extracts of Etlingera elatior on human colorectal carcinoma cells. Malaysian J Chem, 2009; 11(1):136-42.

Wijekoon MMJO, Bhat R, Karim AA. Effect of extraction solvents on the phenolic compounds and antioxidant activities of bunga kantan (Etlingera elatior Jack.) inflorescence. J Food Composition Anal, 2011; 24(4-5):615-9.

Yuan $\mathrm{H}, \mathrm{Ma}$ Q, Ye L, Piao G. The traditional medicine and modern medicine from natural products. Molecules, 2016; 21(5).

Zheng Y, Ley SH, Hu FB. Global aetiology and epidemiology of type 2 diabetes mellitus and its complications. Nat Rev Endocrinol, 2018; 14(2):88-98.

How to cite this article:

Nor NAM, Noordin L, Bakar NHA, Ahmad WANW. Evaluation of antidiabetic activities of Etlingera elatior flower aqueous extract in vitro and in vivo. J Appl Pharm Sci, 2020; 10(08):043-051. 